\title{
Basic modelling of tertiary creep of copper
}

\author{
Fangfei Sui $^{1, *}$ (D) and Rolf Sandström ${ }^{1}$ (I) \\ ${ }^{1}$ Materials Science and Engineering, KTH Royal Institute of Technology, SE-100 44 Stockholm, Sweden
}

Received: 17 November 2017

Accepted: 26 December 2017 Published online:

4 January 2018

(C) The Author(s) 2018. This article is an open access publication

\begin{abstract}
Mechanisms that are associated with acceleration of the creep rate in the tertiary stage such as microstructure degradation, cavitation, necking instability and recovery have been known for a long time. Numerous empirical models for tertiary creep exist in the literature, not least to describe the development of creep damage, which is vital for understanding creep rupture. Unfortunately, these models almost invariably involve parameters that are not accurately known and have to be fitted to experimental data. Basic models that take all the relevant mechanisms into account which makes them predictive have been missing. Only recently, quantitative basic models have been developed for the recovery of the dislocation structure during tertiary creep and for the formation and growth of creep cavities. These models are employed in the present paper to compute the creep strain versus time curves for copper including tertiary creep without the use of any adjustable parameters. A satisfactory representation of observed tertiary creep has been achieved. In addition, the role of necking is analysed with both uniaxial and multiaxial methods.
\end{abstract}

\section{Introduction}

Creep deformation is usually measured by exposing tensile specimens to a constant load or sometimes to a constant stress and recording the elongation of the specimens as a function of time. The result is given as the creep strain versus time, referred to as a creep curve. A creep curve is in most cases characterised by three stages: primary, secondary and tertiary. Creep deformation is induced by the generation, motion and annihilation of dislocations. The creep rate decreases during primary stage, reaches a steady value in secondary creep, accelerates during tertiary creep and terminates at rupture. For many materials, the high initial creep rate is due to a low starting dislocation density. Due to work hardening, new dislocations are generated and the dislocation density increases, leading to a decrease in the creep rate. At the same time, the recovery due to the annihilation of dislocations starts to become of importance. When achieving a balance between recovery and work hardening, the strain rate is approximately constant and the secondary creep stage is reached. It is also referred to as stationary creep. During tertiary creep, a modification of the microstructure occurs, leading to acceleration of the creep rate.

The scientific literature has to a large extent been focusing on the secondary stage due to its direct

Address correspondence to E-mail: fangfei@kth.se 
relation to the operating deformation mechanisms. Much less attention has been paid to primary creep and tertiary creep. Technically, both primary creep and tertiary creep are of utmost importance. For fcc alloys that cover a large fraction of the technically used creep-resistant materials, the creep strain in the primary stage is often of the same order as that in the secondary stage. Tertiary creep is also of major technical significance since it controls creep rupture.

The increase in the creep rate in the tertiary stage due to changes in the microstructure is referred to as the formation of creep damage [1-3]. There are a number of creep damage mechanisms including particle coarsening, subgrain growth, cavitation and recovery of the dislocation structure, which can all accelerate the creep rate during tertiary creep. In addition, the creep rate is influenced by the necking instability. Failure induced by microstructure degradation has been commonly observed in creep-resistant martensitic steels, which have a complex microstructure. During long-term creep, fine carbonitrides (e.g. $\mathrm{M}_{2} \mathrm{X}$ and $\mathrm{MX}$ ) coarsen and dissolve and new brittle phases (e.g. Z-phase, Laves phase, $\mathrm{M}_{6} \mathrm{X}$ carbides) are formed. The absence of fine particles reduces the creep strength. In addition, the new coarser phases can serve as sites for crack nucleation that lowers the creep strength further [4-6].

Good models for particle coarsening [7] and subgrain growth [8] have been available for quite some time. However, for nucleation and growth of cavities, only empirical models involving adjustable parameters had been documented. Only recently, basic quantitative models for nucleation and growth of cavities have appeared [9-11]. The same applies to the modification of the dislocation structure [12, 13].

As a consequence, modelling of creep damage has almost invariably disregarded some important mechanisms and compensated this by using adjustable parameters. It was demonstrated in [14] that by just involving two adjustable parameters, a wide range of creep curves in the tertiary stage could be represented. There are good empirical models for describing tertiary creep. In particular, what is now usually referred to as the omega model can be mentioned [15-17]. However, with two adjustable parameters, a good empirical model is not essential. Many mathematical expressions can be used [14]. This implies that creep damage models with two or more adjustable parameters are not predictive and cannot be used to identify the operating mechanisms.
It is therefore of vital importance that basic equations without adjustable parameters are employed.

Oxygen-free copper alloyed with 50 ppm phosphorus (Cu-OFP) has been selected as canister material for storing spent nuclear fuel in Sweden due to its excellent corrosion resistance and high ductility [18]. During storage, the spent nuclear fuel will release heat while decaying, increasing the temperature up to $100{ }^{\circ} \mathrm{C}$ in the canister. Both hydrostatic pressure and swelling pressure from clay will impact the copper canisters, which will be exposed to creep as a consequence. The copper canisters are expected to stay intact for 100000 years. In order to predict the creep damage under such long times, it is critical to use fundamental models based only on physical phenomena [19]. Cu-OFP is the material that will be investigated in the present paper.

The creep mechanisms at low temperatures (below $0.3 \mathrm{Tm}$, melting point) can be quite different from those at high temperatures. For many materials, logarithmic creep form is more appropriate than power law creep to describe the deformation behaviour. This applies, for example, to austenitic stainless steels, where creep never leaves the primary stage $[20,21]$. However, for copper, this is not the case. A large number of creep tests have been performed for $\mathrm{Cu}-\mathrm{OFP}$ at $75^{\circ} \mathrm{C}(0.25 \mathrm{Tm})$, and the creep curves are quite similar to those achieved at high temperatures, where a well-developed and long-duration steady state is observed [14]. The mechanisms for low-temperature creep are not yet fully established. It has been suggested that low-temperature creep is controlled by glide and cross slip [22]. Dislocation climb was not considered to be active due to the low estimated climb rate at low temperatures. However, if the increase in the climb rate from the increase in vacancy concentration due to plastic deformation is taken into account, the observed creep rates at ambient temperatures for aluminium and copper can be accurately accounted for [23]. If climb is the operating mechanism, the observed extended secondary stage can be explained directly.

In Cu-OFP, changes in the dislocation structure could provide microstructure degradation. Accelerated recovery and an associated decrease in dislocation density as main creep damage mechanism were reported from experimental results [5, 24] and computation [25]. The nucleation of cavities followed by growth and interlinkage is believed to play an important role in creep failure of metals [9, 10]. 
Necking is known as a macroscale deformation inhomogeneity. When the material is plastically unstable, even small defects can promote localised deformation [26]. At some point during creep testing, strain localised in a small region takes place and necking appears. Studies on the effect of an initial defect on creep deformation have been carried out [27-30].

Dislocation recovery mechanism has been used to describe the three stages of creep deformation. Fundamental dislocation models based on this mechanism for primary creep and secondary creep were formulated [14]. It has been demonstrated that it can be used to describe the primary creep and secondary creep of $\mathrm{Cu}-\mathrm{OFP}$ and also slow strain rate tensile tests under both uniaxial and multiaxial stress states [31, 32]. The purpose of the present paper is to model tertiary creep of Cu-OFP taking the relevant microstructure processes into account without involving adjustable parameters. The basis is a model that takes substructure development during creep into account. It was derived originally for coldworked materials and will be employed to simulate accelerated recovery [13]. In order to evaluate the effect of necking on tertiary creep of Cu-OFP, a small imperfection is artificially introduced to the specimen in computation according to the method proposed by Burke and Nix [33]. Influence of cavitation is also considered when describing tertiary creep. The modelled results will be compared with experimental data for $\mathrm{Cu}-\mathrm{OFP}$.

\section{Model}

\section{Accelerated recovery model}

A dislocation model was developed in $[14,32]$ that could describe primary creep and secondary creep of copper. Some parts in the model were taken from the literature for granted but have been precisely derived recently [34]. It is believed that the dislocation model is general. Its validity has been demonstrated also for austenitic stainless steels [35] and for aluminium alloys [23]. By applying the model, it has been shown that the recovery during tertiary creep can be analysed by taking the role of the substructure into account $[12,13]$.

In copper and many other materials, a cell structure is formed during deformation. Already after $10 \%$ strain, the majority of the dislocations can be found in the cell boundaries [36], and after 20\% strain, virtually all dislocations are in the cell boundaries [37]. In the model, only the dislocations in the cell walls are taken into account to avoid an excessive number of parameters. This assumption is also consistent with X-ray measurements done by Straub et al. [38], where the strength contribution from the cell interior is less than $10 \mathrm{MPa}$ for pure copper.

The dislocations in the cell walls are divided into two sets, balanced and unbalanced. This assumption is natural based on the experimental evidence that dislocations in cell walls can be statistically distributed and polarised [39]. In [13], it was proposed that an important content the cell walls is also dislocation locks. This is in agreement with the modelling of strain hardening by Argon [40]. The dislocation locks are primarily Lomer-Cottrell locks, which are pairwise sessile dislocation segments of extended dislocations [41]. When the two sets of dislocation partials slip and meet each other, they form the dislocation locks. The Lomer-Cottrell locks have been frequently observed and are believed to play an important role during strain hardening of fcc alloys [40]. The distinction between balanced and unbalanced dislocations is vital for several properties as will be explained below. In the former set, for any dislocation on a given slip system, a dislocation with the opposite Burgers vector can always be found. The dislocations appear in pairs with opposite Burgers vectors, not necessarily close to each other. In simplified terminology, the numbers of dislocations of opposite signs are balanced. In the latter set, the dislocations are polarised and dislocations of opposite sign are missing. The unbalanced dislocations cannot annihilate each other since dislocations with the opposite Burgers vector are missing. Figure 1 shows a sketch of the formation mechanism for unbalanced dislocations. In a stress-free condition, the dislocations are randomly distributed in the cell interior (Fig. 1a). In the presence of a stress, the dislocations with opposite signs tend to move in different directions. Many dislocations end up on different sides of the cell and form a polarised set around the cell walls (Fig. 1b). These are the unbalanced dislocations. The remainder of the dislocations are considered as balanced. Some of dislocations form cell walls. A number of the dislocations move through the walls [13]. The polarised dislocations with marked sign in Fig. $1 b$ are unbalanced 
(a)

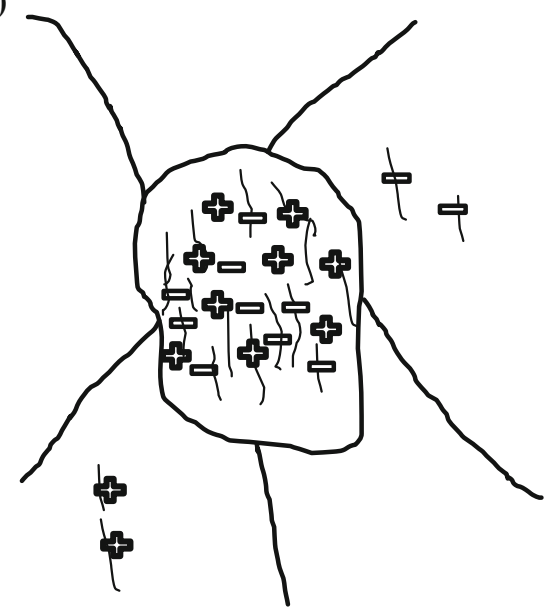

(b)

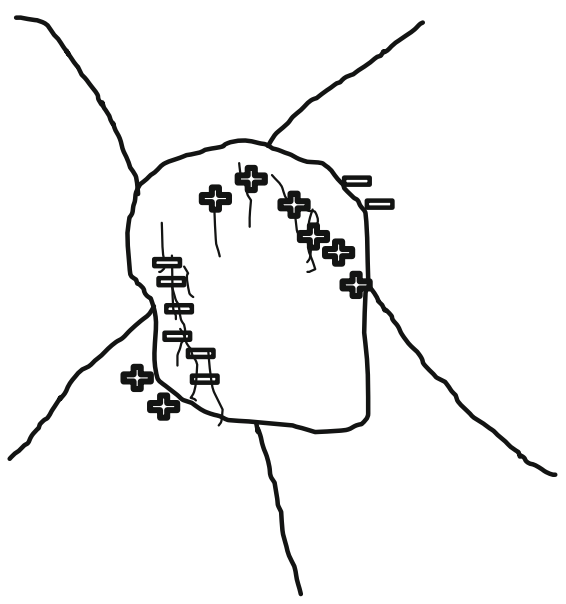

Figure 1 Sketch of formation process of unbalanced dislocations in cell walls.

dislocations. The ones that form dislocation locks in cell walls are balanced dislocations.

The balanced and unbalanced dislocation densities satisfy the following equations $[12,13]$

$\frac{\mathrm{d} \rho_{\text {bnd }}}{\mathrm{d} \varepsilon}=k_{\text {bnd }} \frac{m \rho_{\text {bnd }}^{1 / 2}}{b c_{\mathrm{L}}}-\omega \rho_{\text {bnd }}-2 \tau_{\mathrm{L}} M \rho_{\text {bnd }}^{2} / \dot{\varepsilon}$,

$\frac{\mathrm{d} \rho_{\text {bnde }}}{\mathrm{d} \varepsilon}=k_{\text {bnde }} \frac{m \rho_{\text {bnde }}^{1 / 2}}{b c_{\mathrm{L}}}-\omega \rho_{\text {bnde }}$,

$\rho_{\text {bnd }}$ and $\rho_{\text {bnde }}$ are the balanced and unbalanced dislocation densities in the cell walls, which are defined as the total length of the dislocations divided by the cell volume. $\varepsilon$ is the strain, $m$ the Taylor factor, $b$ Burger's vector, $c_{\mathrm{L}}, k_{\mathrm{bnd}}$ and $k_{\mathrm{bnde}}$ are work hardening constants, $\omega$ a dynamic recovery constant, $\tau_{\mathrm{L}}$ the dislocation line tension, $\dot{\varepsilon}$ the strain rate and $M$ the creep mobility. All the parameter derivations can be found in Refs. [13, 34, 42]. Parameter values are in the "Appendix". The three terms on the right-hand side of Eq. (1) represent work hardening, dynamic recovery and static recovery. It is essential to take both dynamic recovery and static recovery into account when describing tertiary creep as will be evident below. Dynamic recovery is strain dependent while static recovery is time dependent [43]. Dynamic recovery will occur as long as straining takes place [44]. Static recovery describes how dislocations of opposite sign attracted each other and eventually annihilate. Dynamic recovery takes place by the rearrangement of dislocation into lower energy configurations [45]. In the spurt events during plastic straining, the dislocations typically pass through two or more cell boundaries [40,46]. Argon suggests that when dislocations through the cell boundaries, they remove a certain fraction of the dislocation locks, which gives rise to the dynamic recovery effect [40].

Equation (1) has the same format as the basic model for homogeneous dislocations [32]. Since unbalanced dislocations cannot combine with dislocations of opposite Burgers vector, they are not exposed to static recovery. This is the reason for the absence of the static recovery term in Eq. (2). Both unbalanced and balanced dislocations are subjected to dynamic recovery.

A back stress is introduced to model the creep curves. In a number of publications in the past, a back stress has been considered as an intrinsic property that could be measured, for example, in a stress change experiment. With the help of dislocation dynamics simulations, the back stress from dislocations can be computed directly. It turns out that computed back stress is almost identical to the applied stress. This is also the case after a stress drop test. The change in the back stress takes place in less than $1 \mathrm{~ms}$. The difference between the applied stress and the back stress is less than 1/500 of the applied stress [47]. Thus, an intrinsic back stress is not very meaningful to use in modelling, which has been realised by a number of authors, see, for example [48]. Although the back stress cannot be measured, it can be introduced if it is properly defined.

A back stress is introduced in our model as the extra hardening from the unbalanced dislocations in the cell walls [12]. This stress compensates for the sharp increase in true applied stress $\sigma_{\text {appl }}=\sigma_{\text {applo } 0} e^{\varepsilon}$ during secondary creep, where $\sigma_{\text {applo }}$ is the applied 
nominal stress. Only creep testing under constant load is considered here, since all our creep data are for that case. It has been suggested in the literature that testing under constant stress is necessary to achieve a pronounced secondary stage, but that is clearly at variance with our experimental data, see below. It should be recalled that the stress exponent is quite high for creep at lower temperatures, often above 50 [14]. The magnitude of the back stress equals the dislocation stress minus the nominal applied stress $\sigma_{\text {back }}=\sigma_{\text {disl }}-\sigma_{\text {appl0 }}$, where $\sigma_{\text {disl }}$ is given by

$\sigma_{\text {disl }}=\frac{m \alpha G b}{2} \sqrt{\rho_{\text {bnd }}+\rho_{\text {bnde }}}$,

where $\alpha$ is a constant in Taylor's equation, and $G$ is the shear modulus. The effective creep stress is the true applied stress minus the accompanying back stress

$\sigma_{\text {creep }}=\sigma_{\text {appl }}-\sigma_{\text {back }}$

From Eq. (1), an expression for the stationary creep rate can be obtained. In this expression, the creep stress in Eq. (4) should be applied

$\dot{\varepsilon}_{\text {sec }}=2 \tau_{\mathrm{L}} M\left(T, \sigma_{\text {appl }}-\sigma_{\text {back }}\right) \rho_{\text {bnd }}^{2} /\left(k_{\text {bnd }} \frac{m \rho_{\text {bnd }}^{1 / 2}}{b c_{\mathrm{L}}}-\omega \rho_{\text {bnd }}\right)$

If we insert the expression for the back stress into Eq. (4), we find that

$\sigma_{\text {creep }}=\sigma_{\text {appl }}+\sigma_{\text {appl0 }}-\sigma_{\text {disl }}$

We now generalise Eq. (5) by assuming that it is not just valid for secondary creep but for the influence of the changes in the dislocation density on the whole creep, provided Eq. (6) is applied [13]

$\begin{aligned} \dot{\varepsilon}= & 2 \tau_{\mathrm{L}} M\left(T, \sigma_{\text {appl }}+\sigma_{\text {appl0 }}\right. \\ & \left.-\sigma_{\text {disl }}\right) \rho_{\text {bnd }}^{3 / 2} /\left(k_{\text {bnd }} \frac{m}{b c_{\mathrm{L}}}-\omega \rho_{\text {bnd }}^{1 / 2}\right)\end{aligned}$

This approach suggests that if you know the stress dependence of the secondary creep rate, the strain dependence of the creep rate for the creep curve can be derived, provided the variation of the dislocation density is known.

How the different types of stresses change as a function of time is illustrated in Fig. 2 at the applied stress of $175 \mathrm{MPa}$. The three curves in Fig. 2 are calculated from the models described above. Firstly, by integrating the set of Eqs. (1), (2) and (7), creep strain

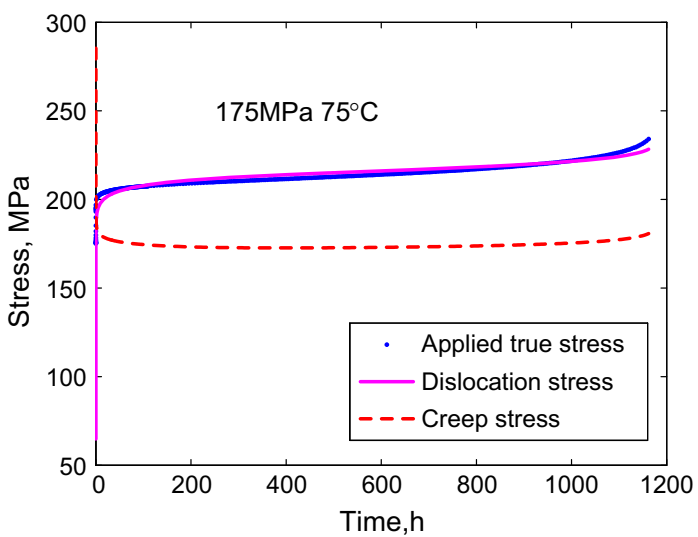

Figure 2 Evolution of dislocation stress, Eq. (3), applied true stress $\sigma_{\text {appl }}$ and effective creep stress, Eq. (6), is given as a function of time for $\mathrm{Cu}-\mathrm{OFP}$ at $75^{\circ} \mathrm{C}$ with an applied stress of $175 \mathrm{MPa}$.

$\varepsilon$, balanced dislocation density $\rho_{\text {bnd }}$ and unbalanced dislocation density $\rho_{\text {bnde }}$ as a function of time can be computed. Then, the applied true stress is obtained by $\sigma_{\text {appl }}=\sigma_{\text {appl0 }} e^{\varepsilon}$, where $\sigma_{\text {appl0 }}$ is $175 \mathrm{MPa}$ in this case. The dislocation stress and creep stress are calculated according to Eqs. (3) and (6), respectively. Initially, the dislocation stress is quite low and the creep stress is high. During secondary creep, the applied true stress is balanced by the dislocation stress (their curves overlap each other during secondary creep as shown in Fig. 2). In the secondary stage, the creep stress is close to the nominal applied stress. In tertiary stage, the increase in the dislocation stress is lower than that of the true applied stress. So the creep stress increases, leading to an acceleration of the creep rate. Dynamic recovery also contributes to the acceleration of creep rate. This is evident from Eq. (7). Since the dislocation stress is increasing, so is the dislocation density. Thus, the dislocation density in the numerator in Eq. (7) increases and the denominator decreases, giving a further increase in the creep rate.

\section{Cavitation model}

Since creep cavitation gives rise to a loss of the load carrying cross section, it can give a contribution to tertiary creep. There are numerous models for nucleation and growth of creep cavities in the literature, but practically all of them involve parameters that are not accurately known and have to be fitted to the observations. Only recently, basic models for nucleation and growth of creep cavities have been formulated by He and Sandström [9, 10, 49]. For a 
review, see [11]. The equations that are used to compute the amount of cavitation are listed and discussed here.

Grain boundary sliding (GBS) is believed to be essential for cavity nucleation. The GBS distance is approximately proportional to the creep strain. The ratio of the GBS displacement rate to the strain rate is a constant, denoted as $C_{\mathrm{s}}$. The value of $C_{\mathrm{s}}$ is approximately $50 \mu \mathrm{m}$ for copper [50]. It is very well established that the number of nucleated cavities is proportional to the creep strain. Already Dyson [51] documented the validity of this relation for a range of materials. It is very difficult to explain the observed stress and strain dependences of cavity nucleation unless GBS is the dominating mechanism [9]. Experiments for GBS demonstrate that about the same value is obtained for $\mathrm{Cu}$ with different experimental techniques from 125 to $600{ }^{\circ} \mathrm{C}$ at different strain rates [50]. It demonstrates that $C_{\mathrm{s}}$ is approximately constant over a wide range of conditions. Nucleation of cavities could take place at particles or at sub-boundaries. Sulphides and oxides can be found in the material. However, the total measured area fraction of particles is less than $1 \times 10^{-5}$, and consequently particles do not play any significant role in cavity nucleation. However, nucleation can take place at the sub-boundary junctions. This has been verified to be thermodynamically feasible [50]. According to the double ledge model, the nucleation rate of cavities is proportional to the creep strain rate, which is in full agreement with experimental data, for example, for austenitic stainless steels [9]. This gives strong support for cavity nucleation being controlled by GBS. The nucleation sites are the intersections of sub-boundaries with sub-boundary corners on the opposite side of a sliding grain boundary. Low angle and twin boundaries are cavity resistant. The cavity nucleation rate at intersections of sub-boundary/sub-boundary corner is [9]

$\frac{\mathrm{d} n_{\mathrm{cav}}}{\mathrm{d} t}=\frac{0.9 \mathrm{C}_{\mathrm{s}}}{d_{\mathrm{sub}}^{3}} \dot{\varepsilon}$,

where $n_{\text {cav }}$ is the number of cavities, $\mathrm{d} n_{\text {cav }} / \mathrm{d} t$ the cavity nucleation rate, $d_{\text {sub }}$ the subgrain size, and $\dot{\varepsilon}$ the creep strain rate.

When the nucleated cavity exceeds a critical size, it will start to grow. The growth of cavities is diffusion controlled driven by stress. Strain-controlled growth has also been considered in the literature, see, for example [52]. In the investigated cases, they give a lower growth rate than diffusion control, and they will not be discussed further. To fix the unphysical exaggerated growth rate predicted by traditional diffusion-controlled cavity growth models, Dyson [53] suggested that the cavity growth rate should not be larger than the creep rate, which is referred to as constrained growth. The constrained cavity growth rate is [54]

$\frac{\mathrm{d} R_{\mathrm{cav}}}{\mathrm{d} t}=2 D_{0} K_{\mathrm{f}}\left(\sigma_{\text {red }}-\sigma_{0}\right) \frac{1}{R_{\mathrm{cav}}^{2}}$,

where $R_{\text {cav }}$ is the cavity radius, $\mathrm{d} R_{\text {cav }} / \mathrm{d} t$ the cavity growth rate, $\sigma_{0}$ the sinter stress, $D_{0}$ a grain boundary diffusion parameter, $K_{\mathrm{f}}$ a factor related to the cavitated area fraction $A_{\text {cav }}$. The parameters values can be found in the "Appendix". $\sigma_{\text {red }}$ is the reduced stress, which can be determined by solving a differential equation [10]

$2 \pi D_{0} K_{\mathrm{f}}\left(\sigma_{\text {red }}-\sigma_{0}\right) / L^{2} R_{\text {cav }}+\dot{\varepsilon}\left(\sigma_{\text {red }}\right)=\dot{\varepsilon}\left(\sigma_{\text {appl }}\right)$,

where $L$ is the cavity spacing. The cavitated area fraction on the grain boundaries can be expressed as [55]

$A_{\mathrm{cav}}=\int_{0}^{t} \frac{\mathrm{d} n_{\mathrm{cav}}}{\mathrm{d} t^{\prime}}\left(t^{\prime}\right) \pi R_{\mathrm{cav}}^{2}\left(t, t^{\prime}\right) \mathrm{d} t^{\prime}$,

where $R_{\text {cav }}\left(t, t^{\prime}\right)$ is the radius of the cavity at time $t$ that was formed at time $t^{\prime}$. It is well established that when the cavitated area fraction exceeds $25 \%$, rupture occurs [56]. In the investigated cases in the present paper, the modelled cavitated area fraction is as low as $0.3 \%$. Its effect on tertiary creep can then be neglected.

\section{Necking model}

At sufficiently large strain during creep, a plastic instability takes place leading to the formation of a waist on the specimen that is usually referred to as necking. Necking is initiated by a geometrical imperfection or a material inhomogeneity in the specimen. Once the waist has been formed, its continuous growth does not depend on how it was initiated. In this analysis, the effect of a geometric defect on the creep deformation is studied.

A necking criterion was proposed by Hart for creep tests under constant load [57]. The onset point of instability can be expressed in terms of area fluctuation. When the variation in the area at a particular point is larger than zero, the deformation is stable. If 
one applies the relation between area reduction and strain, the stability criterion can be expressed as

$\ddot{\varepsilon} \leq \dot{\varepsilon}^{2}$

where $\dot{\varepsilon}$ is the strain rate and $\ddot{\varepsilon}$ is strain acceleration, the second time derivative of the strain. Application of Eq. (12) to the experimental data was carried out for different test conditions to determine the onset of necking.

In a uniaxial model, Burke and Nix [33] analysed necking by considering the deformation response of an initially imperfect cylindrical bar. The initial crosssectional area was assumed to vary along the $x$-axis in a smooth sinusoidal manner according to

$A(x, 0)=A_{0}-\frac{\Delta A}{2} \cos \frac{2 \pi x}{L_{i}} ;\left(0 \leq x \leq L_{i}\right)$,

where $A_{0}$ is the original cross-sectional area of specimen, and $L_{i}$ the length of the specimen with the defect part. $\Delta A$ represents the changes in initial crosssectional area, which is chosen as $\Delta A / A_{0}=0.01$ in the current case. Accordingly, the maximum magnitude of imperfection is $1 \%$. In terms of radius, thus a difference of $0.025 \mathrm{~mm}$ is introduced. By sectioning the specimen along its axis, the creep elongation in each section can be computed directly, since the load on each section is constant and equal to the applied load on the specimen. By adding the elongations of the sections, the creep strain of the specimen can be obtained directly. This average strain for the entire specimen can be used to compare with the experimental result.

Figure 3 shows how the initial strain and initial radius varied along $x$-axis. A symmetric nonuniformity is centred at position $x=0$, varying along $x$-axis to $x=15 \mathrm{~mm}$. At positions $x>15 \mathrm{~mm}$, the initial radius is $5 \mathrm{~mm}$ and initial strain is zero. The gauge length of a tested specimen is $100 \mathrm{~mm}$. So the initial nonuniformity only exists for $30 \%$ axially of the specimen.

When a waist is introduced, the stress state changes from uniaxial to multiaxial. Finite element (FEM) computations were performed to analyse the influence of multiaxiality. Due to limitation in the FEM software, only the secondary stage could be simulated. Severe necking was obtained. Experimental necking profiles were taken from ruptured creep specimens.

\section{Results}

\section{Accelerated recovery results}

By integrating the set of Eqs. (1), (2) and (7), creep strain versus time curves can be computed. All the parameters used in the model can be derived; none is used as adjustable parameter. The derivations of these parameters can be found in previous work Refs. [12-14, 32], and the values are summarised in "Appendix" with references given. The model has been applied to creep curves for Cu-OFP at $75{ }^{\circ} \mathrm{C}$. Experimental data are taken from Ref. [14]. A comparison of the modelled results with experimental curves is shown in Fig. 4. The three stages of creep curves (primary, secondary and tertiary) are present in the experiments. An extended secondary stage is present in spite of the high creep exponent. There are steps in the experimental curves due to the necessity of reloading the specimens when a certain strain was exceeded. Due to the large creep rupture elongation of $\mathrm{Cu}$-OFP, during creep tests the lever arm had to be reset when a critical strain was reached. Otherwise, the lever arm would no longer be sufficiently
Figure 3 Initial strain and initial specimen radius along $x$-axis.
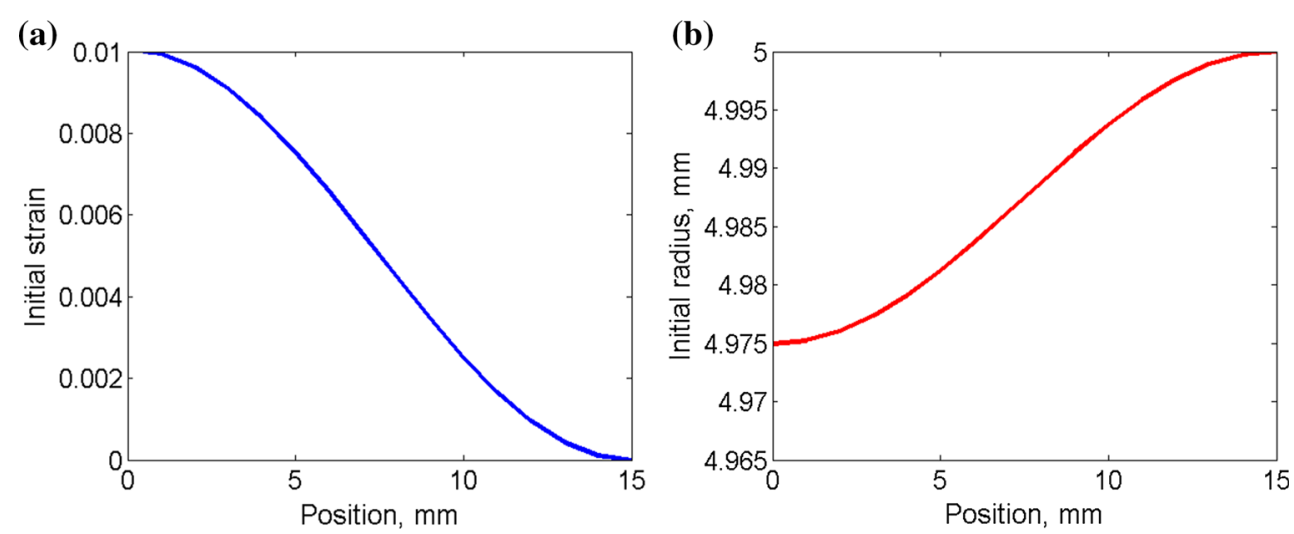
Figure 4 Comparison of experimental creep curve with accelerated recovery model Eq. (7) for $\mathrm{Cu}-\mathrm{OFP}$ a $75^{\circ} \mathrm{C}$, $175 \mathrm{MPa}$; b $75{ }^{\circ} \mathrm{C}, 180 \mathrm{MPa}$.

Figure 5 Modelled creep strain versus time curve for different sectioning elements, denoting as distance from necking centre for $\mathrm{Cu}-\mathrm{OFP}$ at $75{ }^{\circ} \mathrm{C}$ with an applied stress of $175 \mathrm{MPa}$. (a)

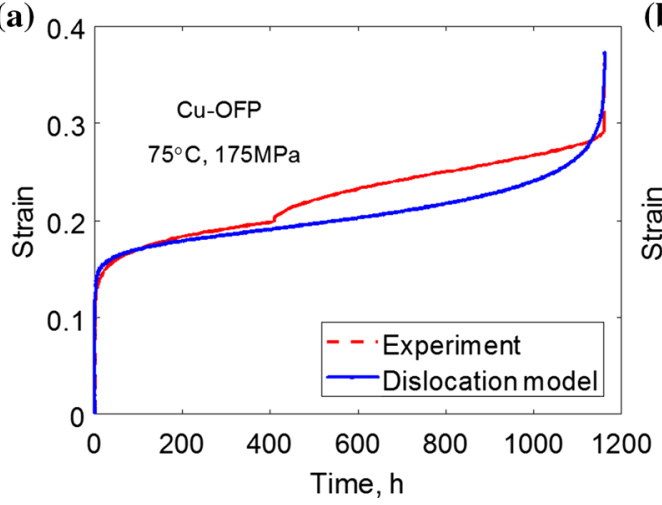

(b)

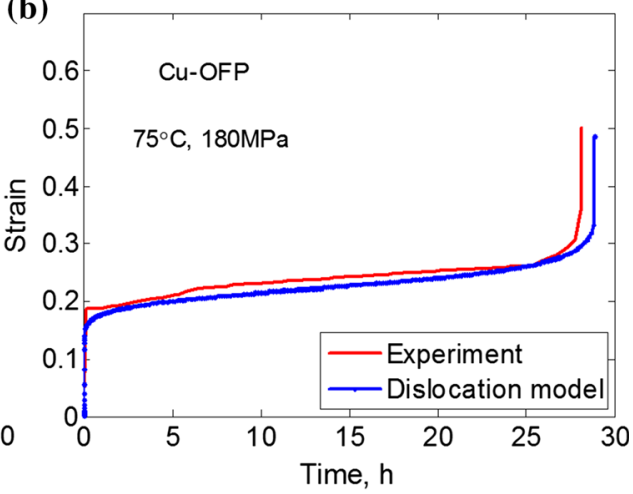

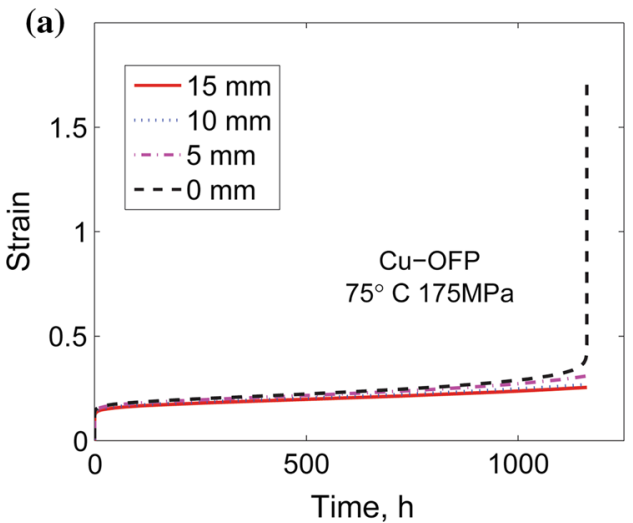

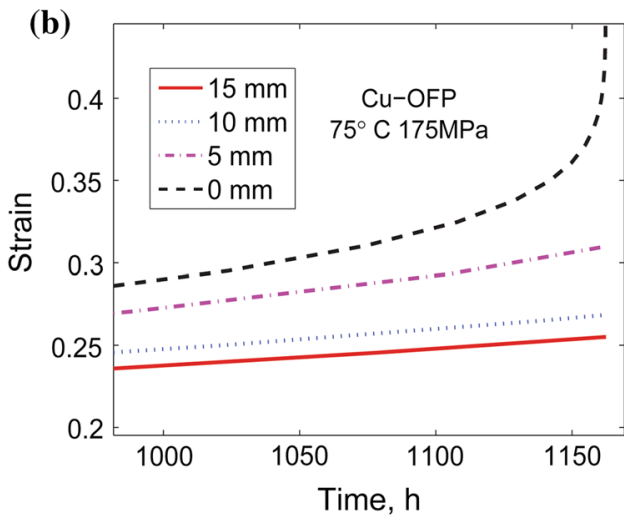

horizontal, and the dead weight might hit the floor. It is believed that during these temporary unloadings, the substructure is relaxed and that is the origin of the small new primary stage that is formed. No attempts have been made to reproduce these steps. The model can describe the three stages in a quite acceptable way. It is interesting to note that the model can describe the logarithmic decrease in the strain rate in the primary stage, which has been observed for a number of materials. This is analysed in [12]. There are some differences at the end of creep life, where the experimental strain increased sharper than the modelled strain. The modelled tertiary stage lasted for longer time and increased more smoothly. This difference will be analysed when the effect of necking is discussed below.

\section{Necking results}

Severe necking was observed on the $\mathrm{Cu}$-OFP specimens after the creep tests, implying that the necking effect should be taken into account when modelling tertiary creep. An initial nonuniform cross-sectional area was introduced to investigate the necking effect on creep deformation of $\mathrm{Cu}-\mathrm{OFP}$.
Both uniaxial and multiaxial analyses have been performed. Figure 5 illustrates the results of the uniaxial analysis. In Fig. 5, modelled creep strain versus time curves are given at different positions, i.e. at different distances from the necking centre. At necking centre, pronounced strain localisation was found and the final strain reached 1.8. The strain can be transformed into the reduction in cross-sectional area according to $\varepsilon=-\ln \left(\frac{A}{A_{0}}\right)$. When the strain is 1.8 , the corresponding reduction in cross-sectional area is around $85 \%$, which is consistent with the experimental measurements for Cu-OFP [14]. Since the curves overlap, a zoom-in view for the time interval from $980 \mathrm{~h}$ to the end of tests is shown in Fig. 5b. The final strain is inversely proportional to the distance from necking centre. At the position of $5 \mathrm{~mm}$ from necking centre, the final strain dropped to 0.31 . This dramatic drop indicates that the strain is localised to a small area. At the positions of $15 \mathrm{~mm}$ and further from the necking centre, the uniform strain was 0.26.

The calculated average strain for the whole sample is used to compare with the experimental curves. The comparison is shown for different test conditions in Fig. 6. An improvement has been achieved for the 
Figure 6 Comparison of experimental creep curve with necking model results for $\mathrm{Cu}$ OFP a $75^{\circ} \mathrm{C}, 170 \mathrm{MPa}$; b $75{ }^{\circ} \mathrm{C}, 175 \mathrm{MPa}$, plus marker indicating necking starting point according to Hart's criterion c $75^{\circ} \mathrm{C}$, $180 \mathrm{MPa}$.

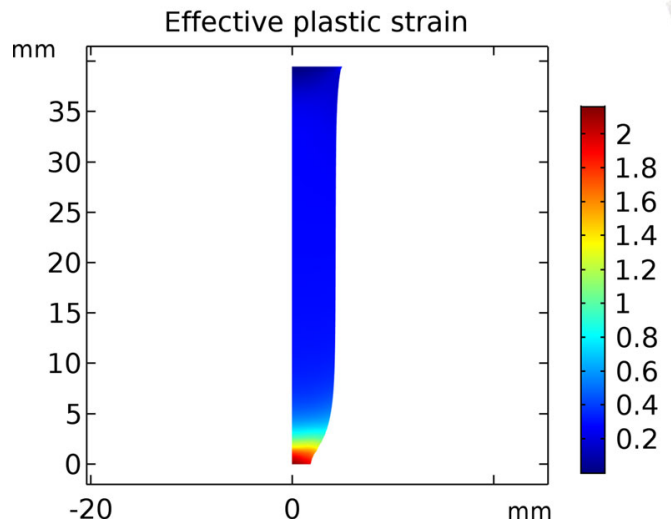

Figure 7 FEM results of strain distribution along the specimen for $\mathrm{Cu}$-OFP at $75{ }^{\circ} \mathrm{C}$ with an applied stress of $175 \mathrm{MPa}$.

end of life in comparison with just the accelerated recovery results. The sharp increase in strain at the end of the tertiary stage can be modelled better by taking necking into account.

Figure 7 shows the strain distribution simulated by FEM at a stress of $175 \mathrm{MPa}$. When the necking phenomenon showed up, the homogeneous strain was 0.27 , which is consistent with the uniaxial result. At the necking position, a localised true strain as high as 2 was found, which is close to both the experimental results and uniaxial computation. In Fig. 8, the total strain versus the uniform strain is given for the same case. The
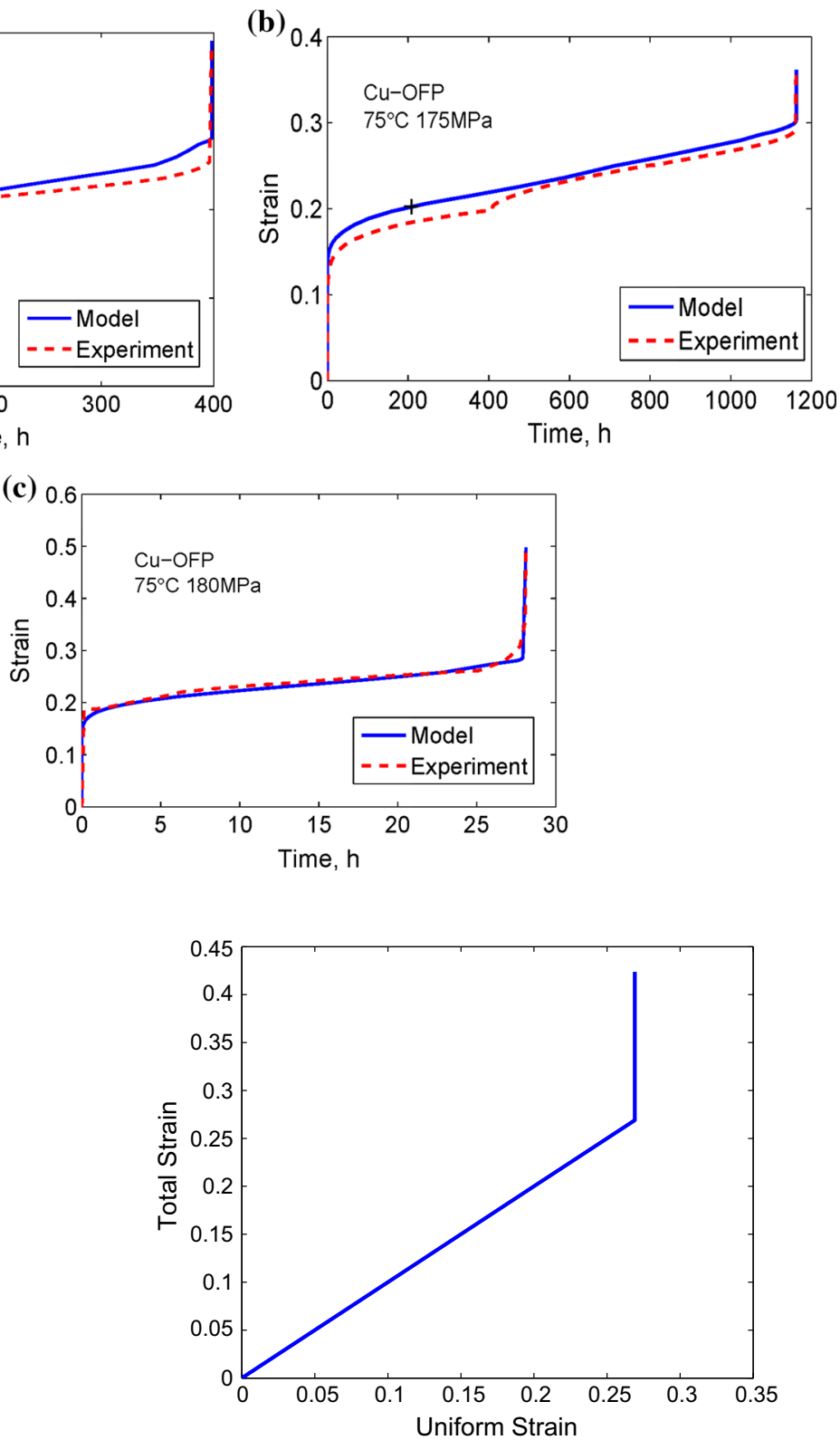

Figure 8 Total strain versus uniform strain for the FEM model in Fig. 7.

figure demonstrates that the deformation is uniform until the deformation becomes unstable and all further elongation takes place in the waist. A real specimen would fail very quickly under these conditions.

Hart's criterion was applied to the experimental data to determine the onset of the unstable deformation. For all test conditions, the unstable deformation starts very close to the inflection point of the strain versus time curve. A plus marker is given in Fig. $6 \mathrm{~b}$ indicating the necking starting point calculated by Hart's criterion. The FEM modelling suggests that the 


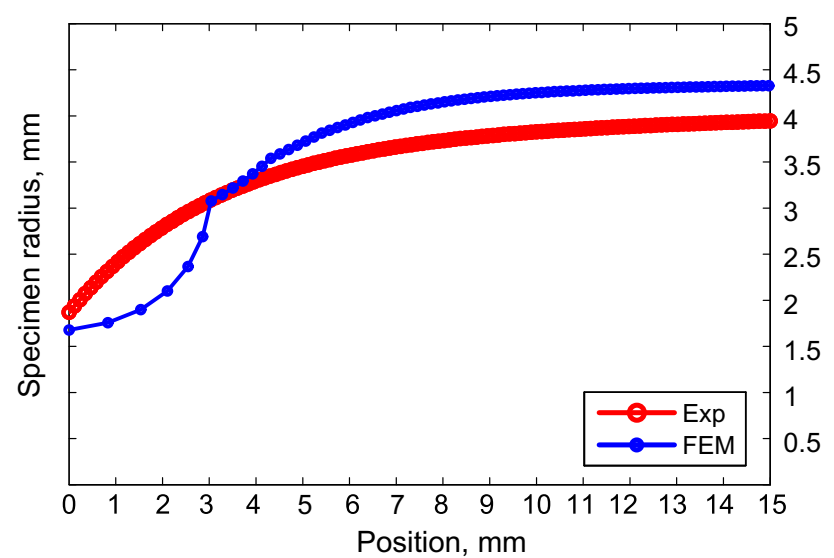

Figure 9 Specimen radius versus axial coordinate at the necking position. Comparison of experimental necking profile with FEM results for $\mathrm{Cu}-\mathrm{OFP}$ at $75^{\circ} \mathrm{C}$ with an applied stress of $175 \mathrm{MPa}$.

necking starts at a very late stage of creep, almost at the failure strain, resulting in a steep rise of the creep curve. The development of the neck is initially obviously quite a slow process.

Figure 9 shows a comparison between the experimental necking profile $(15 \mathrm{~mm}$ along necking position) and the FEM results. The model reproduces the experimental radii within about $10 \%$. The general behaviour is the same and the deviation between them is partially due to the necking elongation in the FEM modelling even after a well-developed neck has been formed. In the real test, the specimen was fractured. So adjacent to the necking position in Fig. 9, the deviation is larger.

\section{Discussion}

There is an extensive literature on the formation of creep damage and its influence on tertiary creep. As pointed out in the introduction, these models are almost invariably empirical. One model that has been used frequently is the one that Riedel presented in his book on creep fracture [58]. He derives the creep damage based on cavity formation. He assumes that the nucleation rate is proportional to the creep strain and that the volume growth rate is linear in time $t$. Also assuming that only secondary creep is of importance, he found that the area fraction of cavities is proportional to $t^{5 / 3}$. This covers the main development of the cavitation in a simple form. However, there are shortcomings. The nucleation rate constant is handled as an adjustable parameter. The effect of constrained growth and possible overlap between cavities is neglected, typically significantly overestimating the amount of cavitation. Today, there is no need to make these simplifications, since the additional effects can be taken into account without much computational effort [11].

The concept that dynamic recovery plays an important role during tertiary creep is relatively new but well established. Creep tests of $24 \%$ cold-worked $\mathrm{Cu}$-OFP were performed at $75^{\circ} \mathrm{C}$ [13]. For all the creep tests, the creep strain versus time curves were dominated by a continuously increasing strain rate, i.e. by tertiary creep. The creep curves could elegantly be reproduced by assuming that dynamic recovery according to a model similar to the one in the present paper was the dominating creep damage mechanisms. Very limited cavitation was observed. This was not surprising since the reduction in area at rupture was almost exactly 90\% (89-91\%).

For the specimens in the present investigation, the reduction in area at rupture was also very high (90-92\%) indicating fully ductile rupture. This indicates that cavitation is of little importance for the failure. This was indeed confirmed by metallographic investigations and modelling. In both cases, the area fraction of cavities in the grain boundaries was less than $0.5 \%$. This makes it natural to assume that dynamic recovery of the substructure is the dominating mechanism for tertiary creep until significant necking quickly develops at the very end of the creep life.

The effects of accelerated recovery, cavitation and necking on tertiary creep have been analysed in the present paper. Accelerated recovery gives the largest contribution to tertiary creep for the investigated alloys. In the model, two distinct sets of dislocations (balanced and unbalanced) are involved. The balanced dislocations are exposed to static recovery, and its density remains approximately constant during secondary creep. At the same time, the unbalanced dislocation density continuously increases and gives rise to a major back stress that matches the continuous increase in the true applied stress. At the end of the secondary stage, the true applied stress increases faster than the back stress. This means that the effective stress rises at the end of the secondary stage, resulting in the increase in the creep rate in the tertiary stage.

Basic models are now available for the nucleation and growth of creep cavities. With these models, the cavitated area fraction of grain boundaries and its influence on the creep curves can be predicted. For the investigated copper alloys, the predicted area 
fraction at failure was less than $0.5 \%$. Consequently, cavitation had no significant influence on tertiary creep.

Uniaxial and multiaxial models for necking have been considered. Hart's criterion [57] indicates that an instability that would give rise to necking is formed directly at the end of secondary creep. This has also well known for other types of materials. For example, Lim et al. [59] found this for 9\% Cr steels. The uniform strain calculated from uniaxial and multiaxial simulations is almost the same. The analyses suggest that significant necking only appears very close to the failure strain. This is also what is found in [59]. Necking simulations give a rapid increase in the strain near rupture in agreement with the observations. Figures $4 \mathrm{a}$ and $6 \mathrm{~b}$ show a comparison of modelled and experimental creep curves for the same case. In both figures, primary creep and secondary creep can be well reproduced. Accelerated recovery exerts the influence on the entire tertiary stage while necking contributes to the very end of tertiary creep. The radii in the neck can be predicted quite well with the help of FEM computations. The model results lie within $10 \%$ of the observed values. In spite of the fact that Hart's criterion gives an early start of the necking, the necking is not really developed until close to failure.

It is expected that the model for tertiary creep is also applicable to other fcc materials than copper. The basic dislocation model has been demonstrated to be valid also for austenitic stainless steels [35] and aluminium [60]. Due to lack of data, it has not been possible to verify that tertiary creep can be represented for these materials. However, the model cannot be used for martensitic 9 and $12 \%$ Cr steels. Tertiary creep is frequently studied in these materials, because of their extensive use in fossil-fired power plants. Tertiary creep in these materials typically show a linear increase in the creep rate with creep strain, see, for example [59]. This behaviour follows what is often referred to as the omega model [15, 17, 61]. Although this empirical model has been known for a long time and the mechanisms involved are well established, it has not yet been derived from basic principles.

\section{Conclusions}

Mechanisms that can contribute to tertiary creep such as microstructure degradation, cavitation, necking instability and recovery have been known for a long time. Empirical modelling of tertiary creep has been performed extensively for understanding the role of creep damage in creep rupture. In the present paper, basic models for tertiary creep are formulated for the relevant mechanisms for copper. Quantitative basic models for recovery during tertiary creep and for the nucleation and growth of creep cavities have only recently become available.

- The most important contribution to creep curves of copper comes from the dislocation structure. A dislocation model is presented that can be used to compute this contribution.

- To be able to describe the contribution from the dislocation structure to the both secondary creep and tertiary creep, there are three important requirements.

- The dislocations in the cell walls must be taken into account.

- Both balanced and unbalanced dislocations must be considered.

- Both dynamic recovery and static recovery must be covered in the equations for the dislocation densities.

- Cavitation often plays an important role in tertiary creep. At the considered temperature $75^{\circ} \mathrm{C}$, the cavitated area fraction is less than $0.5 \%$ and the contribution from cavitation can be ignored.

- The influence of necking on the creep curve has been analysed with uniaxial assumptions as well as with multiaxial methods. It turns that both approaches predict that pronounced necking does not take place until the failure strain has almost been reached. The uniaxial computations give a necking that is narrower than the observed ones. However, the multiaxial approach using FEM predicts a necking that is in good accordance with experiments with computed neck radii within about $10 \%$ of the observed values.

\section{Acknowledgements}

The authors would like to thank Svensk Kärnbränslehantering $\mathrm{AB}$ (Swedish Nuclear Fuel and Waste Management Company, SKB) for financial support [Contract Number 16884] and the China 
Scholarship Council [No. 201307040027] for funding a stipend.

\section{Compliance with ethical standards}

Conflict of interest The authors declare that they have no conflict of interest.

Open Access This article is distributed under the terms of the Creative Commons Attribution 4.0 International License (http://creativecommons.org/ licenses/by/4.0/), which permits unrestricted use, distribution, and reproduction in any medium, provided you give appropriate credit to the original author(s) and the source, provide a link to the Creative Commons license, and indicate if changes were made.

\section{Appendix: Parameter values} See Table 1.

\section{References}

[1] Murakami S (2012) Continuum damage mechanics. Solid mechanics and its applications, vol 185. Springer, Dordrecht (Imprint: Springer)

[2] JunShan Z (2010) Creep damage mechanics. In: High temperature deformation and fracture of materials. Woodhead Publishing, Cambridge, pp 274-284

[3] Altenbach H (1999) Creep and damage in materials and structures. Springer, Vienna (Imprint: Springer)

[4] Vanaja J, Laha K, Mythili R, Chandravathi KS, Saroja S, Mathew MD (2012) Creep deformation and rupture behaviour of $9 \mathrm{Cr}-1 \mathrm{~W}-0.2 \mathrm{~V}-0.06 \mathrm{Ta}$ reduced activation ferriticmartensitic steel. Mater Sci Eng A 533:17-25

[5] Aghajani A, Somsen C, Eggeler G (2009) On the effect of long-term creep on the microstructure of a $12 \%$ chromium tempered martensite ferritic steel. Acta Mater 57(17):5093-5106

[6] Abe F (2004) Bainitic and martensitic creep-resistant steels. Curr Opin Solid St M 8(3-4):305-311

Table 1 Parameters used in this paper

\begin{tabular}{|c|c|c|c|}
\hline Parameter description & Parameter & Value & References \\
\hline Burgers' vector & $b$ & $2.56 \times 10^{-10} \mathrm{~m}$ & \\
\hline Taylor factor & $m$ & 3.06 & \\
\hline Dynamic recovery constant & $\omega$ & 14.7 & {$[14]$} \\
\hline Mobility & $M$ & & {$[42]$} \\
\hline Dislocation line tension & $\tau_{\mathrm{L}}$ & $G b^{2} / 2=7.94 \times 10^{-16} \mathrm{MN}$ & {$[62]$} \\
\hline Boltzmann's constant & $k_{\mathrm{B}}$ & $1.381 \times 10^{-23} \mathrm{~J} / \mathrm{grad}$ & \\
\hline Constant in Taylor's equation & $\alpha$ & $(1-v / 2) / 2 \pi(1-v)=0.19$ with Poisson's ratio $v=0.308$ & {$[63,64]$} \\
\hline Shear modulus & G & $G=45400\left(1-7.1 \times 10^{-4}(T-20)\right) \mathrm{MPa}, T$ in ${ }^{\circ} \mathrm{C}$ & {$[65]$} \\
\hline Work hardening constant & $k_{\text {bnd }}$ & $1.6-1.7$ & {$[12]$} \\
\hline Work hardening constant & $k_{\text {bnde }}$ & $1.6-1.7$ & {$[12]$} \\
\hline Work hardening constant & $C_{\mathrm{L}}$ & 30 & {$[32]$} \\
\hline Grain size & $d$ & $1 \mathrm{e}-4 \mathrm{~m}$ & {$[14]$} \\
\hline Cavity radius & $r_{\mathrm{h}}$ & $1 \mathrm{e}-6 \mathrm{~m}$ & {$[55]$} \\
\hline GBS parameter & $\mathrm{C}_{\mathrm{s}}$ & $50 \mu \mathrm{m}$ & {$[11]$} \\
\hline Subgrain size & $d_{\text {sub }}$ & $\frac{K G b}{\sigma_{\text {appl0 }}}$ with $K=11$ for copper & {$[11]$} \\
\hline $\begin{array}{l}\text { Parameter in the cavitation growth } \\
\text { equation }\end{array}$ & $K_{\mathrm{f}}$ & $\begin{array}{l}\frac{1}{-2 \log A_{\text {cav }}-\left(1-A_{\text {cav }}\right)\left(3-A_{\text {cav }}\right)} \\
\text { where } A_{\text {cav }} \text { is given in Eq. (11) }\end{array}$ & {$[10]$} \\
\hline $\begin{array}{l}\text { Grain boundary diffusion } \\
\text { coefficient }\end{array}$ & $\delta D_{\mathrm{GB}}$ & $\begin{array}{l}\delta D_{\mathrm{GB} 0} \exp \left(-\frac{Q_{\mathrm{GB}}}{R T}\right) \text { with } \delta=2 b, D_{\mathrm{GB} 0}=2.4 \times 10^{-6} \mathrm{~m}^{2} \mathrm{~s}^{-1} \text { and } \\
Q_{\mathrm{GB}}=8.49 \times 10^{4} \mathrm{~J} / \mathrm{mol}\end{array}$ & {$[66]$} \\
\hline Cavity spacing & $L$ & $1 / \sqrt{n_{\mathrm{cav}}}$ & {$[11]$} \\
\hline Atomic volume & $\Omega$ & $1.18 \times 10^{-29} \mathrm{~m}^{3}$ & \\
\hline Grain boundary diffusion parameter & $D_{0}$ & $\delta D_{\mathrm{GB}} \Omega / k_{\mathrm{B}} T$ & {$[10]$} \\
\hline
\end{tabular}


[7] Agren J, Clavaguera-Mora MT, Golcheski J, Inden G, Kumar H, Sigli C (2000) Application of computational thermodynamics to phase transformation nucleation and coarsening. CALPHAD Comput Coupling Phase Diagr Thermochem 24(1):41-54

[8] Sandstrom R (1977) Subgrain growth occurring by boundary migration. Acta Metall 25(8):905-911

[9] He J, Sandström R (2016) Formation of creep cavities in austenitic stainless steels. J Mater Sci 51(14):6674-6685. https://doi.org/10.1007/s10853-016-9954-Z

[10] He J, Sandström R (2016) Creep cavity growth models for austenitic stainless steels. Mater Sci Eng A 674:328-334

[11] Sandström R, He J (2017) Survey of creep cavitation in fcc metals. In: Tomasz Tanski WB (ed) Study of grain boundary character. inTech, Rijeka, pp 19-42

[12] Sandström R (2017) Formation of a dislocation back stress during creep of copper at low temperatures. Mater Sci Eng A 700:622-630

[13] Sandström R (2016) The role of cell structure during creep of cold worked copper. Mater Sci Eng A 674:318-327

[14] Sandstrom R (2012) Basic model for primary and secondary creep in copper. Acta Mater 60(1):314-322

[15] Sandstrom R, Kondyr A (1982) Creep deformation, accumulation of creep rupture damage and forecasting of residual life for three Mo- and CrMo-steels. VGB Kraftwerkstech 62(9):802-813

[16] Sandstrom R, Kondyr A (1980) Model for tertiary-creep in Mo and CrMo-steels. In: Proceedings - computer networking symposium, pp 275-284

[17] Prager M (1995) Development of the MPC omega method for life assessment in the creep range. J Press Vessel Technol Trans ASME 117(2):95-103

[18] Rosborg B, Werme L (2008) The Swedish nuclear waste program and the long-term corrosion behaviour of copper. J Nucl Mater 379(1-3):142-153

[19] Sandström R (2015) Fundamental models for creep properties of steels and copper. Trans Indian Inst Met 69:197-202

[20] Kassner ME, Smith KK, Campbell CS (2015) Low-temperature creep in pure metals and alloys. J Mater Sci 50(20):6539-6551. https://doi.org/10.1007/s10853-0159219-2

[21] Alfredsson B, Arregui IL, Lai J (2016) Low temperature creep in a high strength roller bearing steel. Mech Mater 100:109-125

[22] Kassner ME, Smith K (2014) Low temperature creep plasticity. J Mater Res Technol 3(3):280-288

[23] Sandström R (2017) Fundamental modelling of creep properties. In: Tomasz Tanski MS, Zieliński A (eds) Creep. inTech, Rijeka
[24] Choudhary BK (2016) Microstructural degradation and development of damage during creep in $9 \%$ chromium ferritic steels. Trans Indian Inst Met 69(2):189-195

[25] Vinogradov A, Yasnikov IS, Matsuyama H, Uchida M, Kaneko Y, Estrin Y (2016) Controlling strength and ductility: dislocation-based model of necking instability and its verification for ultrafine grain 316L steel. Acta Mater 106:295-303

[26] Antolovich SD, Armstrong RW (2014) Plastic strain localization in metals: origins and consequences. Prog Mater Sci 59:1-160

[27] Hutchinson JW, Neale KW (1977) Influence of strain-rate sensitivity on necking under uniaxial tension. Acta Metall 25(8):839-846

[28] Kocks UF, Jonas JJ, Mecking H (1979) The development of strain-rate gradients. Acta Metall 27(3):419-432

[29] Levy AJ (1986) The tertiary creep and necking of creep damaging solids. Acta Metall 34(10):1991-1997

[30] Lin IH, Hirth JP, Hart EW (1981) Plastic instability in uniaxial tension tests. Acta Metall 29(5):819-827

[31] Sui F, Sandström R (2016) Slow strain rate tensile tests on notched specimens of copper. Mater Sci Eng A 663:108-115

[32] Sandstrom R, Hallgren J (2012) The role of creep in stress strain curves for copper. J Nucl Mater 422(1-3):51-57

[33] Burke MA, Nix WD (1975) Plastic instabilities in tension creep. Acta Metall 23(7):793-798

[34] Sandström R (2017) The role of microstructure in the prediction of creep rupture of austenitic stainless steels. In: ECCC creep \& fracture conference, Düsseldorf

[35] Vujic S, Sandstrom R, Sommitsch C (2015) Precipitation evolution and creep strength modelling of $25 \mathrm{Cr} 20 \mathrm{NiNbN}$ austenitic steel. Mater High Temp 32(6):607-618

[36] Wu R, Pettersson N, Martinsson A, Sandstrom R (2014) Cell structure in cold worked and creep deformed phosphorus alloyed copper. Mater Charact 90:21-30

[37] Mughrabi H, Ungár T, Kienle W, Wilkens M (1986) Longrange internal stresses and asymmetric X-ray line-broadening in tensile-deformed [001]-orientated copper single crystals. Philos Mag A Phys Condens Matter Struct Defects Mech Prop 53(6):793-813

[38] Straub S, Blum W, Maier HJ, Ungar T, Borbély A, Renner H (1996) Long-range internal stresses in cell and subgrain structures of copper during deformation at constant stress. Acta Mater 44(11):4337-4350

[39] Hughes DA, Hansen N, Bammann DJ (2003) Geometrically necessary boundaries, incidental dislocation boundaries and geometrically necessary dislocations. Scr Mater 48(2):147-153

[40] Argon A (2008) Strengthening mechanisms in crystal plasticity. Oxford series on materials modelling. Oxford University Press, Oxford 
[41] Hirth JP, Lothe J (1982) Theory of dislocations. Krieger Publishing Company, Malabar, FL

[42] Sandström R (2016) Influence of phosphorus on the tensile stress strain curves in copper. J Nucl Mater 470:290-296

[43] Nes E (1997) Modelling of work hardening and stress saturation in FCC metals. Prog Mater Sci 41(3):129-193

[44] Nix WD, Gibeling JC, Hughes DA (1985) Time-dependent deformation of metals. Metall Trans A 16(12):2215-2226

[45] Kocks UF, Mecking H (2003) Physics and phenomenology of strain hardening: the FCC case. Prog Mater Sci 48(3):171-273

[46] Francke D, Pantleon W, Klimanek P (1996) Modelling the occurrence of disorientations in dislocation structures. Comput Mater Sci 5(1-3):111-125

[47] Delandar AH, Sandström R, Korzhavyi P (2017) The role of glide during creep of copper at low temperatures (Subm for publ)

[48] Biberger M, Gibeling JC (1995) Analysis of creep transients in pure metals following stress changes. Acta Metall Mater 43(9):3247-3260

[49] He J, Sandström R (2016) Modelling grain boundary sliding during creep of austenitic stainless steels. J Mater Sci 51(6):2926-2934. https://doi.org/10.1007/s10853-015-9601-0

[50] Sandström R, Wu R, Hagström J (2016) Grain boundary sliding in copper and its relation to cavity formation during creep. Mater Sci Eng A 651:259-268

[51] Dyson BF (1983) Continuous cavity nucleation and creep fracture. Scr Metall 17(1):31-37

[52] Cocks ACF, Ashby MF (1980) Intergranular fracture during power-law creep under multiaxial stresses. Metal Sci 14(8-9):395-402

[53] Dyson B (1976) Constraints on diffusional cavity growth rates. Metal Sci 10(10):349-353

[54] Rice JR (1981) Constraints on the diffusive cavitation of isolated grain boundary facets in creeping polycrystals. Acta Metall 29(4):675-681
[55] Sandström R, Wu R (2013) Influence of phosphorus on the creep ductility of copper. J Nucl Mater 441(1-3):364-371

[56] He J, Sandström R (2017) Basic modelling of creep rupture in austenitic stainless steels. Theoret Appl Fract Mech 89:139-146

[57] Hart EW (1967) Theory of the tensile test. Acta Metall 15(2):351-355

[58] Riedel H (1987) Fracture at high temperatures. Springer, New York

[59] Lim R, Sauzay M, Dalle F, Tournie I, Bonnaillie P, Gourgues-Lorenzon AF (2011) Modelling and experimental study of the tertiary creep stage of Grade 91 steel. Int J Fract 169(2):213-228

[60] Spigarelli S, Sandström R (2018) Basic creep modelling of aluminium. Mater Sci Eng A 711:343-349

[61] Sandstrom R, Kondyr A (1979) Model for tertiary creep in Mo and CrMo steels. In: Miller KJ, Smith RF (eds) 0.5Mo, $1 \mathrm{Cr}-0.5 \mathrm{Mo}, 2.25 \mathrm{Cr}-1 \mathrm{Mo}$ SACM, Chromium molybdenum steels 31 mechanical properties, ICM 3, Cambridge, England, pp 275-284. Pergamon Press, Oxford

[62] Dieter GE (1986) Mechanical metallurgy. McGraw-Hill, Boston

[63] Orlová A (1991) On the relation between dislocation structure and internal stress measured in pure metals and single phase alloys in high temperature creep. Acta Metall Mater 39(11):2805-2813

[64] Horiuchi R, Otsuka M (1972) Mechanism of high temperature creep of aluminum-magnesium solid solution alloys. Trans Jpn Inst Met 13(4):284-293

[65] Ledbetter H, Naimon E (1974) Elastic properties of metals and alloys. II. Copper. J Phys Chem Ref Data 3(4):897-935

[66] Surholt T, Herzig C (1997) Grain boundary self-diffusion in $\mathrm{Cu}$ polycrystals of different purity. Acta Mater 45(9):3817-3823 